Accepted for publication at the journal The Monist (14 ${ }^{\text {th }}$ September 2018).

\title{
Race and the responsibility to abide by the norms of unchosen and unjust social roles
}

Joseph Kisolo-Ssonko

The University of Nottingham

Joseph.Kisolo-Ssonko@ nottingham.ac.uk

\begin{abstract}
Charles Mills claims that there are specific 'civic and political duties' which individuals have a responsibility to fulfil because of the racial social roles they occupy. However, even those generally sympathetic to Role Ethics resist the idea that such nonvoluntary and morally problematic roles could ground genuine normativity. I argue that we should take the felt normativity of non-ideal social roles seriously. Further, I argue that we should agree with Mills that one's race constitutes a social role with normative force. However, I claim that Mills is wrong to seek to ground this normativity in an actual social contract (the 'racial contract') and I argue instead that Margaret Gilbert's account of joint commitment, and its accompanying notion of collective intentionality, can be developed so as to provide a more promising proposal. I conclude that the responsibility to abide by the norms in question is better understood as grounded in the individual role holder's involvement in the collective intentionality of the relevant racial class.
\end{abstract}

\section{Social Roles and Normative force:}

If you are a parent you should read your child a bedtime story. If you are a taxi driver you really ought to take me home via the most efficient route. It might be tempting to say that the agents here have these obligations merely because of their abilities to achieve the assumedly desirable outcomes in question, but that is clearly not right. That I can read to children does not, on its own, generate a reason for me to find any child and read to them. Likewise, that I have a car and can drive does not, alone, give me a reason to give any stranger who hails me a lift. We might propose that what makes the taxi driver different from someone who merely could drive a taxi is that they are a taxi driver. Similarly what makes the parent different from someone who merely could parent is that they are a parent. In this vein we could say that, there are distinctive normative implications which are generated - at least in part - by the occupying of certain social roles: an occupant of such a role has special normative reasons to act in certain ways that do not exist for non-occupants even when they find themselves in similar circumstances. To say this is to say that the parent has reasons qua parent and the taxi driver has reasons qua taxi driver.

The broadly, and quickly, sketched account above expresses the core commitments of 'role ethics'. The attractiveness of such commitments is far from universally acknowledged. As Michael O. Hardimon notes, many contemporary moral philosophers have "... neglected these obligations, regarding them as marginal at best" (1994, p.333). In fact, much contemporary philosophy, with its universalist and agent neutral aspirations, actively denies the possibility of there being any special 
normative reasons of this sort. The debate here is large and doing it full justice would require settling many meta-ethical debates. ${ }^{1}$ Rather than tackling the general challenge of saying what it is about occupying any social role that means that, qua occupying a role, someone has special reasons, I suggest we might ask particular questions such as, what is it about being a parent that means that a parent qua parent has reason to read to their child? I see no reason to presume from the outset that the answer with regard to any one particular social role, or class of social roles, need be universal in application to others. Perhaps what grounds the special reasons of a parent is fundamentally different from what grounds the special reasons of a taxi driver. In asking these questions one need not presume that it will turn out to be possible to give any good answers for any social roles, though I do presume that it is at least not absurd to seek them. That is, I assume that Role Ethics is a worthwhile research programme despite its apparent clash with some of the presumptions of contemporary moral philosophy. In this paper, for reasons that I will explore below, I will be focusing on the social role of having a particular racial status.

Whilst noting that such enquiry has been termed 'Role Ethics', I will proceed with the project of looking for the grounding of the special reasons of racial roles without presupposing that, if they exist, these reasons must be part of the special class of reasons we call 'moral reasons'. With this in mind, rather than talk of special-obligation, special-entitlements, special-requirements, specialrestrictions, special-permissions and so on, I will talk generally about the agent in question having 'special-reasons', here noting that I mean this to capture this wide variety of normative phenomena. I will use the term 'normative force' to refer to the extent to which a social role gives special normative reasons to the agent. By 'special' I mean merely that in the relevant circumstances the role-occupyingagent would have reasons that an agent who did not occupy that role would not have even when in the same circumstances and having the same abilities and capacities. ${ }^{2}$

Using the terminology set out above, non-general 'role ethical' questions can thus be posed in a more neutral fashion as: what grounds the normative force of particular social roles? As noted already, I do not presume that the answer need be the same for each social role. But, tentatively, I also want to make a bolder claim: the kinds of answers that look promising for different roles look likely to be different. For example, for some roles the most promising sounding answers might evoke the efficiency of assigning certain tasks to only certain individuals for the production of some global good (happiness perhaps). You might think that the parent role fits such a story. In contrast, for other roles the most promising sounding answer might claim that the role gains its normative force in virtue of its occupants contracting to fulfil the duties embedded in it. This might plausibly be thought to apply to the taxi driver. Further, other roles might gain their normative force in a yet different fashion, e.g. from the structures of the games they are embedded in. Think, say, of a defender in a football match.

1 A comprehensive list of literature dealing with this debate has been collated by the Role Ethics Network and can be found at https://roleethics.org/literature-guide/.

2 Such a formulation, it might be noted, need not even cut off the possibility that all the 'special-reasons' of social roles turn out to fully reducible to some function of universal agent neutral normativity - though, in the case of racial social roles I argue that this is, in fact, not the case. 
Whilst it might be the case that all of these normative forces are ultimately grounded in a single non-instrumental good, a pluralist approach looks more promising. Such pluralism gains more plausibility if it is noted that talk about the normative force of these roles need not imply that they provide compelling all-things-considered reasons for actions. Rather, we can see them as providing merely pro tanto reasons to perform certain actions. It may well be that the taxi driver qua taxi driver has a reason to drive me home, but if doing so would mean he misses his daughter's graduation then this would conflict with his reason qua parent to leave me by the side of the road and perhaps, all reasons (both role generated and universal) considered, this is what he should do. Clearly in a case where the taxi driver's potential fare is a right-wing gun enthusiast on the way to murder 50 innocent people it seems highly intuitive to say that the requirements of universal morality, rather than any role he occupies, are what give the driver all-things-considered reason not to provide a lift. However, noting the force of such intuitions need not require claiming that any reasons qua taxi driver no longer exist. Instead we can just note how heavily outweighed they would be in such cases.

Having set the scene, I can now move on to the motivation for examining racial social roles. Aside from its being interesting in their own right, what might be gained from such an investigation? The easiest cases to gravitate towards, by which I mean the cases that fit most easily into the commonplace individualist outlook shared by most analytic philosophers, ${ }^{3}$ are those similar to the two I gave above (i.e. parent and taxi driver). These are roles that appear to fulfil either a just, or at the very least a useful, social function. They are also roles that are to some extent optional for their inhabitants, that is to say that there appears to be some level of voluntary choice involved in the role occupant's occupation of their role. ${ }^{4}$ For many of the kinds of plausible stories, which might be told about the grounding of the normative force of these roles, such facts are likely to be important. For instance, one might think that it is some kind of combination of the fact that you have committed to becoming a fire-fighter, the fact that you have accepted training for that profession and the fact that saving people from fires tends to make the world a much better place, is the key to the grounding of the normative force of the social role fire-fighter. ${ }^{5}$

A corollary thought to the above is that, where a role is either unjust or unchosen there is no need to search for what grounds the normative force of those roles because such roles clearly have no normative force. This, it seems to me, is wrong-headed. Whilst, in the final analysis, it may transpire that the apparent normative force of such unjust or unchosen roles is illusory, many such roles certainly feel as if they come packaged with specific obligations and entitlements; e.g. it certainly does not seem outrageous to suppose of the criminal gang member (a role clearly unjust and possibly unchosen) that she has a reason, qua being a gang member, to adhere to and enforce obedience to the virtue of 'not snitching'. Much more could be said about such an example and intuitions about it will differ, however, there is at least an apparent phenomenon calling out for explanation. So whilst the final analysis might turn out to be an error theory which eliminates the phenomenon - for example, the feeling that one ought to follow the gangs commands might be based on a false belief that the gang is morally virtuous - there is no prima facie reason to suppose that the

3 And indeed the cases that actually are most frequently invoked in the role ethics literature.

4 Though of course one can become a biological parent by accident.

5 Here I mean not what justifies the existence of the role 'fire-fighter' but rather what makes it the case that occupying the role gives one special-reasons. 
feelings do not reflect an actual normative phenomena and that we might discover the facts that ground this phenomena.

In this fashion, I see no prima facie reason to accept what Jeske calls 'voluntarist' worries that special normativity can only ever arise "... through the voluntary actions of the agent whose obligations they are" (2014). ${ }^{6}$ That even the individual who was press-ganged into becoming a gangster could have $a$ reason not to snitch is made more plausible by repeated emphasis of the point made above: we are talking about merely having some reason, not necessarily having any kind of allthings-considered reason. If we assume some over-riding power of the good of individual freedom, we might want to say that all-things-considered all the reasons generated by unchosen roles are always and in every single case outweighed by counterpoising reasons. However, even this would give us no reason to suppose that they do not have pro tanto normative force. It certainly does not appear to necessarily signal conceptual confusion on an agent's part to suppose that they could fail to see the role they occupy as just, or at least be quietest on the matter, and yet still believe it to give them pro tanto reasons to do particular things.

Shifting from the unchosen-ness of the gangster role to its unjust nature might trigger stronger counter-intuitions. Indeed, if you find it offensive to imagine that there could ever be any reason even a pro tanto reason that is in fact outweighed in every instance - to do morally repugnant things then I fear we may have reached a hard-to-pass clash of intuitions. Perhaps though, the rest of the paper will still make some sense if you replace my talk of normative force with normative force*, where normative force* is a kind of milque-toast normativity ${ }^{7}$ i.e. a kind of normativity that does provide an agent with reasons but not full-blooded heavyweight 'moral' type reasons.

Note that I do not intend here to have refuted someone who is a sceptic about special gangsterrole reasons or their kin, rather I seek merely to have opened up a space for the possibility of such reasons. The main point here is just that the possibility of there being normative force for unjust or unchosen roles is easier to imagine once we grasp that there is no need to accept what Hardimon calls the "doctrine of perfect adequacy" (1994, p.338). That is, we need not maintain that for social roles to have any normative force they must provide a perfectly adequate guide to action.

One last preliminary issue that is worth considering (before I move on to talk about the normative force of racial roles) is that, as Hardimon notes, "[n]ot every status is a role. The statuses of human being or person, for example, are not roles. To speak of the obligations we have as human beings or persons as role obligations is a confusion." (1994, p.334) One might make a similar argument about racial status, one might claim that to speak of 'the role obligations of a white person' is clearly confused. Here, I have to delay response to this complaint by noting that Charles Mills makes a striking case that such claims are not confused, indeed, that they are very fitting indeed. This I will explore below. However, even whilst he cautions against assuming that all statuses are roles, Hardimon's restriction to 'institutional roles' is actually far from clear-cut and Mills, as we will see below, does think that race is an institution.

6 Note Jeske talks about special 'obligations' rather than 'normativity'; I'm using the term voluntarism here slightly more widely but, I take it, in the same spirit.

7 Thanks to Sarah Stroud, McGill in her talk at the Third Role Ethics workshop (2017) for the evocative name. 
Hopefully I have made a case for the possibility that some unchosen or unjust roles have normative force, that said, they will no doubt be more tricky, controversial and perhaps difficult to understand than those roles that are closer to some kind of ethically ideal set up. Why then not just ignore them, or at least put off their investigation, until we have got to grips with the simpler more ideal type of roles? Could they not be left to be analysed using whatever conceptual framework we generate through investigation of the 'easier' cases? Is there not a general analytical principle: use the clearest cases to construct your theory and issue a promise to solve the hard cases later? While not engaging with the exact question, as I put it here, Charles Mills - whose work on race will be my focus below - provides a rationale for ignoring any such principle and engaging with social life in its very non-ideal form. Mills' claim, simply put, is just that most of social life really is far from ideal. Focusing on the more ideal roles $^{8}$ then, in Mills own words, risks “... abstract[ing] away from relations of structural domination, exploitation, coercion, and oppression, which in reality, of course, will profoundly shape the ontology of [the individuals in question], locating them in superior and inferior positions in social hierarchies of various kinds." (2005, p.168) Failing to grasp this reality is to theorise in what Mills calls an 'ideal-as-idealized-mode' (2005, p.69) the chief crime of which he argues is that it necessarily neglects the real experience of the actual normativity found in the genuinely oppressive social world.

In terms of the current enquiry, as I have framed it above, I take it that Mills' claims can be read as meaning that, instead of merely examining what kinds of idealised role might generate normative force in idealised circumstances, we should examine and take seriously the normative force of the social roles that actual people actually occupy in real, and far from ideal, circumstances. Below, I will argue that the social roles associated with race are exactly the kinds of roles that can tell us much about real-(thoroughly-non-ideal)-world normativity.

\section{Mills 'racial contract' and the 'civic and political duties' of racial roles.}

It would be unfair to say that social philosophy has completely ignored race but, at least within certain circles, its importance has been only minimally reflected. Given the prominence of race in shaping the social lives of so many, one might wonder why discussion of race is not more eminent or indeed why it has been neglected for so long? One possible answer is that, as Albert Atkin puts it, race has been seen as something that is part of the "extraneous details"; something to be "abstracted away" (2012, p.4). What might it mean then, when asking questions about social roles, to stop doing this? Mills claims that when we stop ignoring race we come to see that it isn't an irrational deviation from the correct ways of thinking about normative worlds, rather it is a fundamental factor in how the normative world actually is.

Of particular interest to the project I am pursuing here, is Mills' idea that we can usefully reconstruct the beating heart of the main normative theories which make use of the notion of a social

8 Or at least assumed to be ideal. It may be that, once our conceptual lens has been opened to the centrality of oppression in social ontology we see that even supposedly unproblematic roles like taxi-driver and parent are fraught with power structures in the actual world. 
contract in some way ${ }^{9}$ by noting that there is in reality a kind of actual social contract: the racial contract. For Mills this racial contract is "... that set of formal or informal agreements ... between the members of one subset of humans, henceforth designated ... as white and coextensive (making due allowance for gender differentiation) with the class of full persons, to categorise the remaining subset of humans as 'non-white' and of a different and inferior moral status." (1997, p.11) For Mills there is no one singular expression of this actual contract, rather it is formed in different ways in different times and places. The most easily concrete expressions - to be found in Mills' writings - are examples that are written in the American context, no doubt partly because of the centrality that racial roles played in the formation of that country, but also because it is the place with the most advanced academic study of race. Race, Mills correctly notes, has been integral to shaping the "identities, interests, and ideals" of every American citizen (2015). He gives a myriad of different and detailed historical examples throughout his work.

For Mills, assigning a race to each person is to assign them a social status. The relevant question is then: what - if any - specific normative force does each racial social role have attached to it? Here Mills' main assertion is merely that such roles, contra to all the doubts that 'color blind' liberal philosophers might have, really do have such normative force. To take a key quotation, he says that, "... [ $\mathrm{t}$ ] o the extent that those phenotypically/ genealogically/ culturally categorized as white fail to live up to the civic and political duties of capital $W$ whiteness they are in dereliction of their duties as citizens" (1997, p.14 [emphasis mine]). What though are these supposed to be? This, it has to be admitted isn't completely clear from Mills' work. One thing to note is that just as the contract is thought to be enacted in different ways in different times and places, there also need be no absolutely fixed truth about the matter of the contents of the roles it creates. Racial roles are neither natural kinds nor natural functions. They fulfil a social function: the function of the domination of one class of people, as a class, over another class of people. However, the ways of fulfilling this function are sure to be multiply realisable and, given this, it is unsurprising that the norms might shift with time, location and the specific historical needs of the role.

There are, however, some suggestions - which are to be found throughout Mills' work - of the characteristic kinds of norms that are often in play. One example Mills gives is of the norm of 'purity' (2005, p.176). White people, according to Mills, will feel the normative push of the norm that they should preserve the 'purity' of the white race. This is less obvious now than in the past but it is possible to find contemporary examples. For example, the potent imagery and symbolism relating to a imagined the threat of immigration deployed by certain factions in the recent debate about 'Brexit' in the UK (think of the Brexit campaign photo of Nigel Farage standing in front of a poster depicting a flood of dark skin people). Another example Mills gives is of autonomy. Autonomy, which for Mills can be most readily pictured in the archetype of the Wild-West pioneer, is a particularly raced value because the white man is presumed to be free to reason as if he stood free from the community of values that condition him - to pretend to be what we might call an 'abstract individual' - because he has actual material freedom and mastery. Similarly, to be white is to claim to embody the norm of

9 Note that Mills' reading of what constitutes the Social Contract Tradition is rather heterodox and spans theorists from Kant to Rawls. He - at least in the key work under consideration (Mills, 1997) - makes no particular note of any distinction between contractualist and contractarian type positions. 
neutrality - a norm which again only makes any sense given the occupation of a position of actual dominance from which one's own position is safe from dissolution.

At this point, even if it is granted that race exists as a social role rather than just social status, it might be complained that it is wrong to see the above-presented norms as part and parcel of the social role "white person". Rather, it might be argued, these norms are merely sets of values the acceptance of which is - non-accidentally, but not by way of constitution - correlated with the social roles in question. What I have in mind here can be seen with the following comparison: being a fisherman is clearly a social role; suppose that we boldly claim that, “... the philosophy of fishing needs to move beyond any abstract characterisation of being a fisherman and instead look at the reality of occupying such roles for actual role occupiers"; undertaking such a project might lead us to find that fishermen have rough hands. Would this mean we could say that, or even that we have found any evidence for the claim that, the social role 'fisherman' contains some sort of requirement or even push towards the attribute of having rough hands? No. Clearly there is a correlation and this occurs because of the nature of the work of fishing - pulling the ropes etc. However not as a constituent feature of the role, rather because the features that are core to the role are likely to result in most participants having such hands. The nature of fishing may be within the social roles, the consequences of living this nature are surely not. A similar claim then would be that the social role "white person" does not contain - as part of the role itself - any sort of normative requirement that its bearer abides by the norms of purity, autonomy or neutrality (or any such). Rather - and here much of the argument that Mills makes about the political function of these norms in the maintenance of white power could be maintained - the correlation occurs merely because of the nature of the social system in which the role exists - being inside certain kinds of power relations is likely to result in individuals voluntarily accepting these values because they allow the individual who occupies the role position to excuse their own behaviour, or perhaps just because they seem to follow naturally from the functioning of the system that the role is part of when combined with the idea (the false idea of course) that it is a normatively well functioning system.

Mills, however, is at pains to deny that these norms are in anyway additional to the social roles in question rather than integral to them. That is, these norms are not distinct add-ons, or mere foreseeable consequences, but rather part and parcel of the social roles in question. Thus it is not a matter of choosing values that fit well given the purpose of the racial social roles. Rather, as Mills notes, the "... terms of the Racial Contract norm nonwhite [and white] persons themselves"10 (1997, [emphasis mine]). His justification for this claim is the repeated presentation of the actual facts of these roles, of their actual historical and social functioning.

I expect that, even for some of those largely sympathetic to Mills' descriptions of the centrality of race to actual normativity, there may still be some resistance here. The resistance may stem from the idea that there could be no possible ground for the normative force in question. In a presentation of a version of this paper a white audience member seemed bemused at the idea that, qua white person, she could possibly have any reason to be racist (as seems to be implied). The naturalness of this

10 'Norm' is here being used as a verb. I am assuming that it makes sense to interpret Mills here in terms of the norms attaching to the person qua role holder, though arguably the quote might be taken to imply that he takes the norms to apply directly to the individual as individual. However, the former reading seems the more charitable to me. 
reluctance, it seems to me, is why Mills plays so heavily on at times a rather strained image of an actual contract. Perhaps if we could ground the normative force of these roles in an actual contract then this would make some sense - even if the roles themselves are oppressive and thoroughly unjust. As Hardimon notes, in the teeth of a general reluctance to accept the idea of role normativity (to use my terminology), social roles that are based on "signing on" for the roles from which the normativity derives are seen as less problematic (1994, p. 337).

It is thus understandable for Mills to make use of the contract theory: it lends respectability to what is to many a shocking philosophical thesis. However, his use of it inherits a problematic individualism from that type of normative theorising. As Sally Haslanger has claimed, what we might aptly (but slightly opaquely) call the 'Ideology of Individualism' (2015) is endemic within much of what passes as analytic philosophy. Part of what this means is that there is a general focus on the individual as the locus of action when it comes to the ontology and normativity of the social world. Now one might reasonably reject the whole notion that such ideology is problematic, however if we accept Mills' particular method of describing the non-ideal social world, then it looks like we really also ought to reject individualism, since Mills' claim that we can understand an individual only in the context of their social situation is aimed to be a break from the idea that we can make sense of an individual's states - such as their contractual commitments - qua individual. The problem is that, when it comes to theorising the 'Racial Contract', Mills seems to fall back into relying on something that does appear to assume this ideology.

Mills' own view on the foundation of the normative force of racial roles is not clear. The general impression he gives is that it is the chosen self-identification - the 'solidarity' as he calls it (1997, p.114) - between people raced as white that underpins the normative force of the racial contract. This solidarity is held in place by the fact, Mill claims, that as a group (though not necessarily individually) white people benefit from this racial contract. Importantly, though the benefit of the contract explains why the solidarity exists, it is still the solidarity itself that directly underpins the normative force of the roles. When Mills says such things as "[t]o the extent that nonwhites accept [the racial social identities]... they also were signatories to the Contract" (1997, p. 118), he appears to be claiming that it is the existence of (semi)literal 'signatories' to the racial contract that underlies the normative power of racial roles. In this he is wrong: there are no such literal contracts that define the nature of racial roles and yet the racial world still exists.

But if the normative force (of these roles) is not grounded in individual choice - that is, these roles are not primarily given force by signing up to a contract - how is it grounded? If the normativity doesn't come from individual opt-in, where does it come from? Below, my proposal is that we may be able to locate the normative force of racial social roles in the collective intentionality that comes with what I call the we-ness of the role. This account relies on a particular understanding of collective intentionality that I will not be able to fully argue for here, however I hope at least to present it as a compelling possibility. ${ }^{11}$

11 I argue for this understanding more fully in Kisolo-Ssonko, 2015 


\section{Joint commitment and normative force}

In her book, 'A Theory of Political Obligation' Margaret Gilbert (2006) is far from unique in noting a dilemma for social contract theory (understood in the same broad sense that Mills understands it). On the one hand, if the contract in question is seen as being merely hypothetical then we must note that "... it is probably not true, that from the premise that people would have agreed to something if asked, or given other more restrictive conditions, one can infer that they have obligations to do what they would have agreed to do" (Gilbert, 2006). On the other hand, if the contract is understood as needing to be actual, then we have to acknowledge that actually "... most people have not agreed" (Gilbert, 2006, p.71). This problem is well-known and numerous attempts have been made to circumvent it. Gilbert's more unique contribution is the particular solution she proposes, what she calls her 'Plural Subject Theory of Political Obligation' (Gilbert, 2006, pp. 238-286). According to this theory, rather than a contract, hypothetical or actual, political obligation is in fact underpinned by “... an underlying joint commitment to accept certain rules” (Gilbert, 2006, pp. 238239).

The relevance of Gilbert's alternative to social contract theory to our current investigation of the normative force of racial social roles is that, regardless of whether Gilbert is correct to think that her account can explain obligation to the state (the traditional target of social contract theory), it may well be able to explain this particular instance of social normativity. Indeed, I'll suggest below that the idea of racialised joint commitment, and the accompanying notion of racialised collective intentionality, provides an account of racial social roles that is more promising than Mills' racial contract explanation.

There are many different definitions of collective intentionality but let us take Schweikard \& Schmid's wide definition as our starting point:

"Collective intentionality is the power of minds to be jointly directed at objects, matters of fact, states of affairs, goals, or values ... Collective intentional attitudes permeate our everyday lives, for instance when two or more agents look after or raise a child, campaign for a political party, or cheer for a sports team. And these attitudes ... play crucial roles in the constitution of the social world." (Schweikard \& Schmid, 2013)

The idea then is that, rather than merely having individual agentive attitudes, of the sort 'I will $x$ ', or 'I am $x$-ing', what are important in these cases are attitudes of the kind 'we will $x$ ', or 'we are $x$-ing'.

So what does this have to do with the possibility of racial roles having normative force? Gilbert claims that we should understand collective intentionality as created through joint commitment. Further she claims that once we have done so we will see that collective intentionality creates specific obligations. Individual intentionality, we might say, is the result of individual will. My act of going for a walk on my own is an intentional act because it reflects my commitment to do so. My walking is an expression of my intention to walk. For Gilbert collective intentionality is created by a plurality of agents jointly committing. Imagine a couple taking a walk together. For Gilbert what makes their walking an expression of collective intentionality - something more than merely travelling in 
proximity (temporal and/or spatial) - is that the agents can be said to have jointly manifested and accepted "... willingness to constitute with the other a plural subject with the goal that they travel in each other's company" (Gilbert, 1992, p.163). The reason collective intentionality constrains the plurality of agents is, for Gilbert, the same as the reason individual intentionality constrains the individual: if I fail to go for the walk, for which I have made (and not rescinded) a personal commitment to go on, I am doing something wrong. That this is neither a moral nor broadly pragmatic wrong can be seen by noting that I might have formed the individual intention to push over an old lady (which would be morally reprehensible), or I might have formed the intension to cut myself (which would have a negative effect on my health). But in both of these cases, the fact that objectively speaking we should not value the intended ends does not appear to change the fact that if I do intend them and yet fail to be constrained by those intentions, in some sense I am in error. ${ }^{12}$ Gilbert's claim is that, similarly to failing to go on the walk you individually committed yourself to (and didn't individually rescinded), if I fail to play my part in the walk we have jointly committed to (and we haven't jointly rescinded) then (in the same way) I do something (non-instrumentally, non-morally) wrong.

How do we get from the collective intentionality of walkers to the collective intentionality of racial groups? Well, the argument must be made that, in so far as the 'white' individual is part of the collective we that exists in 'we white people', they are - at least qua their being as a part of that we bound by the collective intentionality of it. i.e. bound by what we white people desire/want/intend etc. Belonging to a we in this sense captures, or so I argue, exactly the kind of bond that Mills thinks is needed to ground racial norms. If then we are using 'solidarity' in the sense that Mills does ${ }^{13}$ then we can say that being joined together with others in a we is to stand in a relationship of solidarity with them. Note, the important point that the 'white' individual is not just any individual who has certain characteristic features - say whiteness of skin and whatever else is meant to come with this - rather the individual we are interested in is the one who lives the social role 'white' person. The colour of their skin may be the feature that lets them do this - i.e. lets them be 'white' - but being $a$ 'white' is not merely having this colour skin. This difference can be seen more readily if we note the difference between, what Gilbert calls, 'summative wes' and 'non-summative wes'. ${ }^{14}$

Summative wes are short-hand for referring to all of the individuals but still as individuals. When we say things such as "we all want to win the lottery" we are clearly talking in a summative sense. All we mean to say is that each of us individually wanted to win, we certainly don't want everyone to win (then the pot of money would be shared out to only a very small amount each). These types of 'we's do not seem to generate social roles, or to put it another way, they are not themselves expressions

12 Where I discuss these examples in (Kisolo-Ssonko, 2015) I attempt to ground this wrongness in Micheal Bratman's planning theory of agency, such that there are intrinsic reason for self governance which ground being constrained by your own intentions - even where such self governance involves morally or pragmatically "bad ends" (see Bratman, 2004, p. 443). Here (in line with Gilbert herself) I leave this exactly how this wrongness is grounded is more open. This need not undermine the argument as long as the reader is willing to continuance that there is some sense in which 'commitments of the will' (Gilbert's terminology) to can ground wrongs (this issue is discussed further below).

13 Here we divorce the term form implications of a feeling of sympathy for fellows that it ordinary has, such that - for example - gang members who hate each other still exist in a relationship of solidarity in as much as they see themselves as united together.

14 Terminology borrowed from Margaret Gilbert (see 1999, but used throughout her work). 
of social role membership. Think for example of the class of all the red haired people in Edinburgh. Red-haired-in-Edinburgh is not a social role in the same way that being black is. Which is not to say that there are not also summative groups which overlay this - i.e. each individual who has a certain shade of skin. We might say then that, to return to Mills' terminology again, summative wes need not be relationships of solidarity.

Now let us turn to non-summative wes. These are wes as plural subjects: i.e. as collectives of individuals that share collective agency (at least in some minimal sense). Examples where we can see with relative ease the difference with summative wes include "We voted to go on strike". In such a case, some of us individually voted not to strike and thus it is not summatively true to say that we each voted in this way; however, because the majority voted to go on strike it is true non-summatively to say that collectively we committed to walk out. Here the statement is about the collectivity as a collectivity, what Gilbert would call a plural subject.

So what does a non-summative we have that a summative we lacks? You might think that it just comes down to the importance of the shared characteristic - perhaps that the characteristic represents an objective actual sharing of interests. However, for Gilbert, there must be something more than the objective sharing of interests in a distributive sense. The correctness of Gilbert's position may be obscured by the way in which sociologists and political theorists sometimes group together certain sets of people and talk of them as united by their shared characteristics. For example, Marxist social theorists see the set of people with common economic interests, due to their need to work for a wage and their lack of ownership of the means of production, as being united as a social class (namely, the working class). Nevertheless, it is not clear that such theorists mean to suggest that the working class is socially united in the sense I am trying to capture. Indeed Karl Marx's repeated calls for the working class to unite appear to imply that merely sharing the characteristics that make them the working class, does not mean that they are already united. ${ }^{15}$

All of which is not to claim that mere sets - i.e. summative wes cannot have sociologically important causal impacts. The fact that the set of people living on this soggy island (UK) as a majority have a certain skin tone has impacts on the amount of sun-cream that will be sold in an unseasonally hot summer. However, the objective social importance of their shared characteristics does not in itself make them automatically into something that is socially united. As Gilbert puts it, having "... a shared way of life and common interests ... alone cannot be said to make a population into a collectivity" (Gilbert, 1992, p.39).

There is something then to forming a non-summative we, a collective in a strong sense of that word and for Gilbert this shared sociality is precisely to be found in the existence of collective intentionality generated by joint commitment. Suppose that we accept this, there is - as already noted above - a further move that Gilbert makes that gets us from the existence of collective intentionality to normative power: the constraining force of personal commitment.

15 See for example Marx, 2000, p.252. 
Let us return to Gilbert's example of a pair of walkers: suppose that a couple are engaged in a long walk to the top of a hill. As time drags on one of them becomes bored and announces to the other that they intend to abandon the endeavour. "You can't give up", the other reacts, "We said we would walk to the top!" According to Gilbert's account, the way in which the keen walker expresses their complaint, suggests that it is not grounded on the errant walker's expressed intention being in conflict with their own intention as such (though it may well be in conflict). Rather, the keen walker's complaint appears to be grounded in the conflict between the errant walker's expressed intention and an intention that they collectively hold, namely, their intention as a couple to walk to the top of the hill. The example of the walkers, Gilbert believes, shows that when there is dispute between that which is required by the collective intention and that which is required by the individuals own intention, an individual can be rebuked if they act on their personal intention against the collective intention. Such a rebuke is legitimate because it is a response to that individual's transgression of what Gilbert calls their “... obligation not to act contrary to the shared intention” (2000, p.17).

Now the term 'obligation' carries with it a strong moral and 'all-things-considered' flavour, however Gilbert wants us to see this obligation as akin to that which an individual has towards their own individual intentions. That is, just as an individual who intends to $x$ has a pro tanto obligation to act in such a way as to bring about $x$, a member of a collective that intends to $y$ has the same kind of obligation to act in such a way to bring about $y$. In this way, when Gilbert speaks of forming a collective intention as involving 'joint commitment', she does not mean to indicate any external obligating force, moral or otherwise. Instead she means to indicate a commitment of the will, albeit a joint rather than individual will.

How do we form these kinds of joint wills other than being two people going on a walk together? Gilbert thinks that we do so commonly. Gilbert allows for the possibility that becoming involved in a joint will can be much more subtle and elongated over time than signing up to a contract could ever be. Such subtle expressions are evident in the ways we communicate in the everyday social world. Expressions such as "We citizens see this piece of paper as money"; "for us English, it's not football if you are allowed to pick up the ball". She exploits this possibility when she is arguing that we can consider the nation state as a plural subject:

“... it is common knowledge ... that in face-to-face conversations, letters, and so on everyone speaks without hesitation of 'our country', 'our constitution', 'our laws', and so on in relation to the population as a whole. They speak of what 'we' are doing in terms of both international relations and internal issues. They evince guilt, pride, and other such emotions over such things. And they give no indication that they do not wish the plural subject interpretation to be made." (Gilbert, 2006, p.244.)

Whilst Gilbert does not construct an argument about racial roles she does (buried in a footnote) give what strikes me as a wonderful example that in fact highlights the plausibility of one: Native American Tonto's reply (in the popular 1950's television series) to the Lone Ranger's inclusion of him within the scope of the use of the term we; "We, white man?". As Gilbert notes: "We' is often used to emphasize or create a sense of group membership. Political rhetoric abounds with such phrases as 'We Americans' and 'We trade unionists'. And compare Tonto's reply to the Lone Ranger: 'We, 
white man?""16 (Gilbert, 1996, p.198). The assumption that Tonto disrupts is that the we in these phrases can be read as a 'non-summative $w e$ ' rather than a 'summative $w e$ '. In the current context we could think of such expressions as: "We blacks need to fight for equality"; "We need there to be more BME students recruited"; "... as black philosophers we have an obligation to help each other succeed in the profession." The above is intended firstly as an illustration of how racial roles might fit neatly into a Gilbert-like picture of a social world constructed through joint commitment. It also illustrates that what $I$ have argued is the key reason for moving from the racial contract to racialised collective intentionality, i.e. the fact that joint commitment, in Gilbert's picture, does not require explicit agreements.

We need not accept Gilbert's claims that this works for a nation state to see how a case could be made for understanding racial groups in this way, however there is an element that I think Gilbert misses out in this explanation that becomes even more prominent in the case of racial groups. This is the compulsion and the contradiction we can feel in using 'we' in these cases. So while Gilbert says that 'everyone' speaks without hesitation of 'our' country, this in fact misses out the immigrant and ethnic minority experience. Sentences like "Oi Niggers, this is our country!" and their possible resonance undercut her claim that there is no 'hesitation'. Indeed the example she herself gives of Tonto's reply to the Lone Ranger: 'We, white man?' seems to embody this hesitation.

Accepting the complication of varying levels of identification with the collective, as implied by varying levels of hesitation in speaking of the 'we', might be seen as undermining Gilbert's picture. Indeed, a plural subject account does seem far simpler if one thinks that there just either is such a subject, or there is not. However, there seems no reason not to suppose that there can be levels of collective agency, and even where the sense of we is contested and fragile there is still some sense in which there is a kind of collective intentionality which can be ascribed to these kinds of social groups. In fact, this alternative actually fits better with a sensible understanding the normative power of racial roles because it allows racial roles - and their attending normative force - to be other than all or nothing. In contrast, a contract seems either to be signed or not signed.

\section{Conclusion:}

For many philosophers, the idea that we have any special responsibilities that are generated by our social roles is problematic. I have suggested that a fruitful way to address this is to look to explore what might ground particular types of roles, rather than just asking the larger more general question. It might be thought that the best roles to focus on are the 'simpler' ones, those that are more voluntary and less morally problematic. However, I have argued that there is much to be gained from looking at more socially 'real' roles, such as racial roles. In exploring race as a social role with normative force I have argued that we can understand Mills as claiming that the normative force of certain unjust and

16 It has been suggested to me that the quote was never in the original television series but, in fact, originates from a cartoon in Mad Magazine. Further, that it may not have been a joke about racial group inclusion per se. I cannot find a reliable source these claims but do not think they change the relevance of the example. Moreover, the phrase certainly exists as a piece of folk law, with very clear connotations about racial inclusion/exclusion, within the nonwhite cultural consciousness of my locale. 
involuntary social roles (or at least race) is grounded in the existence of an actually existing oppressive contract (e.g. the racial contract). Such an explanation would be good if it worked, because it would fit the assumption of some that the most secure foundations for social role obligations are those that are generated by actual contracts. However, I have argued that this is problematic because though such roles do exist and though they do indeed have the normative force he claims, there is no underlying agreement made which could possibly be the ground for this normative force.

Margaret Gilbert claims that we can reinterpret social contract theories of political obligation which suffer from the same key problem that no actual social contracts are agreed - with plural subject theory which requires no such sign-ups. Even if we reject Gilbert's claims about the state, we can mirror her argument very neatly with regard to racial roles by reinterpreting Mills' talk of a racial contract which, (as I have put it) grounds the normative force of the racial roles it creates, with plural subject theory. This is advantageous because we do actually form racially segregated $w e$ 's in the plural subject sense and this dose not suffer from the key problem that no actual racial contract is agreed.

If we accept this then we can say that the normative force of non-just involuntary social roles is grounded in the individual member of that role's involvement in the collective intentionality of that group. 


\section{Bibliography}

Atkin, Albert (2012) The Philosophy of Race, Routledge

Gilbert, Margaret (1992), On Social Facts, Princeton University Press. Reprinted with minor alterations from Hardback edition (1989), Routledge

- (1996) "Walking Together: A Paradigmatic Social Phenomenon"

- (2000) "Introduction: Sociality and Plural Subject Theory", in her Sociality and Responsibility, Roman \& Littlefield pp.1-13

- (2006) A theory of political obligation, Oxford

Hardimon, Michael O. (1994) “Role Obligations” Journal of Philosophy 91 (7):333-363.

Haslanger, Sally (2015) "Social structure, narrative and explanation, Canadian Journal of Philosophy, 45:1, 1-15, DOI: 10.1080/00455091.2015.1019176

Jeske, Diane, (2014) "Special Obligations", The Stanford Encyclopedia of Philosophy, Edward N. Zalta (ed.), URL $=<$ https://plato.stanford.edu/archives/spr2014/entries/special-obligations/>.

Kisolo-Ssonko, Joseph, (2015) 'How Where We Stand Constrains Where I Stand' Institutions, Emotions, and Group Agents, Contributions to Social Ontology, Philosophical Studies Series, Vol. 121, Konzelmann Ziv, Anita; Schmid, Hans Bernhard (Eds.) Springer, Dordrecht

Marx, Karl. (2000), Karl Marx: Selected Writings, Compiled by McLellan, D., Oxford

Mills, Charles W. (1997), The racial contract, Cornell University Press

- (2005) “'Ideal Theory' as Ideology”, Hypatia, Volume 20, Issue 3. pp 165-183

- (2015), "Breaking the Social Contract", Dissent Magazine, Online

Schweikard, David P. \& Schmid, Hans Bernhard (2013) "Collective Intentionality" The Stanford Encyclopedia of Philosophy 